\title{
Identification of a Vibration Regime Favorable for Bone Healing and Muscle in Estrogen-Deficient Rats
}

\author{
Marina Komrakova $\cdot$ Stephan Sehmisch • Mohammad Tezval • Jan Ammon • \\ Peggy Lieberwirth · Cordula Sauerhoff • Lukas Trautmann • Michael Wicke • \\ Christian Dullin · Klaus M. Stuermer · Ewa K. Stuermer
}

Received: 11 September 2012/ Accepted: 21 January 2013/Published online: 17 February 2013

(C) The Author(s) 2013. This article is published with open access at Springerlink.com

\begin{abstract}
Numerous whole-body vibration (WBV) devices of various forces are available on the market, although their influence on the musculoskeletal system is not yet understood. The effect of different WBVs on bone healing and muscle function was evaluated in rats ovariectomized at 3 months of age. 2 months after ovariectomy, bilateral meta+ physeal tibia osteotomy and T-plate osteosynthesis were performed. Rats were divided into groups: intact, OVX, and OVX exposed to vertical WBVs of $35,50,70$, or $90 \mathrm{~Hz}$ (experiment 1) or horizontal WBVs of $30,50,70$, or $90 \mathrm{~Hz}$ (experiment 2) 5 days after osteotomy $(0.5 \mathrm{~mm}, 15 \mathrm{~min} /$ day for 30 days). The tibia and gastrocnemius and soleus muscles were collected. Vertical vibrations $(>35 \mathrm{~Hz})$ improved cortical and callus densities, enlarged callus area and width, suppressed the tartrate-resistant acid phosphatase gene,
\end{abstract}

The authors have stated that they have no conflict of interest.

M. Komrakova ( $₫)$. S. Sehmisch · M. Tezval · J. Ammon ·

P. Lieberwirth - C. Sauerhoff - L. Trautmann ·

K. M. Stuermer - E. K. Stuermer

Department of Trauma Surgery and Reconstructive Surgery,

University Medical Center Goettingen, Robert-Koch 40,

37075 Goettingen, Germany

e-mail: komrakova@yahoo.com

M. Wicke

Department of Animal Science, University of Goettingen, Albrecht-Thaer-Weg 3, 37075 Goettingen, Germany

C. Dullin

Department of Radiology, University of Goettingen,

Robert-Koch 40, 37075 Goettingen, Germany

\section{E. K. Stuermer}

Institute for Research in Operative Medicine, Faculty of Health, School of Medicine, Witten/Herdecke University, Cologne, Germany enhanced citrate synthase activity, accelerated osteotomy bridging (35 and $50 \mathrm{~Hz}$ ), upregulated the osteocalcin (Oc) gene $(70 \mathrm{~Hz})$, and increased relative muscle weight $(50 \mathrm{~Hz})$. Horizontal vibrations reduced cortical width $(<90 \mathrm{~Hz})$ and callus density $(30 \mathrm{~Hz})$, enhanced alkaline phosphatase (Alp) gene expression $(50 \mathrm{~Hz})$, decreased the size of oxidative fibers (35 and $70 \mathrm{~Hz})$, and increased capillary density $(70,90 \mathrm{~Hz})$. Biomechanical data; serum Oc, Alp, and creatine kinase activities; body weight; and food intake did not change after WBVs. Vertical WBVs of 35 and $50 \mathrm{~Hz}$ produced more favorable results than the higher frequencies. Horizontal WBV showed no positive or negative effects. Further studies are needed to elucidate the effects of WBV on different physiological systems, and precautions must be taken when implementing WBV in the treatment of patients.

Keywords Whole-body vibration - Osteoporosis . Bone healing $\cdot$ Muscle $\cdot$ Ovariectomized rat

\section{Introduction}

Whole-body vibration (WBV) treatments are becoming increasingly common in sports and rehabilitation [1]. WBV has been introduced as a noninvasive, nonpharmacological therapy for osteoporosis due to its anabolic effects on musculoskeletal tissue [2]. Numerous clinical studies have shown a significant improvement in bone mineral density (BMD) after WBV treatments in postmenopausal women with osteopenia and osteoporosis [3]. Maintenance of bone strength and density during aging is highly dependent on the maintenance of adequate muscle mass and function. A loss of muscle strength leads to physical frailty, which increases the risk of falls that lead to osteoporotic fracture. Estrogen status has a profound influence on fracture 
healing and muscle properties. When a fracture occurs in estrogen-deficient individuals, bone healing is delayed and the recovery of the muscle after inactivity is slowed $[4,5]$.

Physical exercise is considered an effective strategy for the recovery of muscle and bone after trauma, and it is frequently recommended in general practice. However, in elderly people, exercises may induce arduous stress on bone and increase the risk of injuries, especially in osteoporotic patients. Furthermore, studies have shown that it is difficult to encourage elderly people to exercise. Elderly women are often too weak to perform physical exercise. For these patients, WBV may be an option to stimulate the recovery rate of muscle and bone regeneration. Mechanical stimuli have been shown to promote fracture healing by stimulation of new bone formation [6]. Muscle mass, muscle strength, and muscular performance and balance have been enhanced after WBV treatments [7].

Today, many WBV devices of various forces (vertical, sinusoidal, or horizontal) are available on the market; however, it is unknown what type of vibratory signal is necessary to achieve a beneficial response from muscle and bone [8]. The effects of different vibration-loading parameters (frequency, magnitude, duration) on the musculoskeletal system are well understood, partly because of the large variability in the vibration regimes used in clinical and experimental trials. Different vibration regimes can either stimulate bone healing or impair the bone regeneration process $[9,10]$. Similarly, WBV may exert beneficial or adverse effects on muscle tissue [10].

We investigated the effect of vibration regimes of different frequencies (30-90 Hz) and types (vertical or horizontal) on bone healing and muscle function in ovariectomyinduced osteopenic rats.

\section{Materials and Methods}

\section{General Procedures}

All procedures were approved by the local regional government according to the German animal-protection laws. Animal experiments and data analyses were performed at the University Medical Center of Goettingen. 3-month-old female Sprague-Dawley rats (Harlan Winkelmann, Borchen, Germany) were housed in groups of four or five in standard cages under a 12-hour dark-light regime at a temperature of $22 \pm 1{ }^{\circ} \mathrm{C}$. Animals received a standard pellet diet (ssniff Special Diet; ssniff, Soest, Germany) and water without restrictions throughout the experiments. Food consumption and body weight (BW) were recorded weekly during the experiment. One week after delivery and acclimatization, the rats designated as healthy controls were left intact. Rats that were assigned to the severe osteoporotic groups underwent bilateral ovariectomy under intraperitoneal ketamine and xylazine anesthesia ( 115 and $8 \mathrm{mg} / \mathrm{kg} \mathrm{BW}$, respectively). Rats were housed for 8 weeks to induce osteoporotic conditions in the ovariectomized (OVX) group [11]. Thereafter, a bilateral osteotomy of the tibial metaphysis with T-plate osteosynthesis was performed under ketamine and xylazine anesthesia in all rats [12]. Briefly, both tibiae were osteotomized transversally $7 \mathrm{~mm}$ distal of the knee surface with the aid of a pulsed ultrasound saw (Piezosurgery ${ }^{\circledR}$; Mectron Medical Technology, Carasco, Italy). A 5-hole, T-shaped titanium plate fixed the osteotomized bone ends with the aid of four screws at the ventromedial aspect of the tibia. Plates and screws were obtained from Stryker Trauma (Selzach, Switzerland). During the operation, rats received perphenazine (Decentan; Merck, Darmstadt, Germany) and carprofen (Rimadyl; Pfizer, Kar1sruhe, Germany) subcutaneously (100 and $4 \mathrm{mg} / \mathrm{kg}$ BW, respectively). Carprofen was given twice a day for 2 postoperative days. Fluorescent dyes were injected subcutaneously to label the new bone formation at the site of the osteotomy. Xylenol orange ( $90 \mathrm{mg} / \mathrm{kg} \mathrm{BW}$, Merck) was injected on day 13 , calcein $(10 \mathrm{mg} / \mathrm{kg} \mathrm{BW}$; Chroma/Waldeck, Muenster, Germany) was injected on day 18 , alizarin complexone (30 mg/kg BW, Merck) was injected on days 22 and 24, and tetracycline ( $25 \mathrm{mg} / \mathrm{kg}$ BW; Roth, Karlsruhe, Germany) was injected on day 35 after osteotomy [13]. 5 days after osteotomy, rats were exposed to the different vibration treatments.

In experiment 1 , the effect of vertical WBV at different frequencies on bone healing and muscle was studied. There were six groups of rats (15 rats each). Group 1 served as an intact control (intact). Group 2 served as an osteoporotic control (OVX). In groups 3, 4, 5, and 6, OVX rats were treated with either $35,50,70$, or $90 \mathrm{~Hz}$ of vertical vibration, respectively. Vibrations were applied using a previously described device [10] consisting of a vibration desk, two alternating current engines, and a force transducer that adjusts the vibration frequency from 35 to $90 \mathrm{~Hz}$.

In experiment 2 , the effect of horizontal WBV of different frequencies on bone healing and muscle was investigated. Rats were divided into the following treatment groups (15 rats each): (1) intact rats, (2) OVX, (3) OVX rats treated with $30 \mathrm{~Hz}$ horizontal vibration, (4) OVX $50 \mathrm{~Hz}$, (5) OVX $70 \mathrm{~Hz}$, and (6) OVX $90 \mathrm{~Hz}$. Vibration treatments were conducted using a newly developed vibration device (Vibra Maschinenfabrik Schultheis, Offenbach, Germany) consisting of a vibration desk, two alternating current engines attached to the one side of the desk, and a force transducer to change the vibration frequency between 30 and $100 \mathrm{~Hz}$.

In both experiments, rats (seven or eight at a time) were vibrated in a plastic cage $(50 \times 50 \times 25 \mathrm{~cm})$ that was attached to the vibration desk. The vibration regime was as follows: 15 min once a day for 30 days. The amplitude of the vibrations was $0.5 \mathrm{~mm}$. Nonvibrated rats were handled the same as the experimental groups excluding the vibration treatments. 
35 days after osteotomy, rats were decapitated. Blood samples were collected and stored at $-20{ }^{\circ} \mathrm{C}$ until analyses. The uterus was extracted and weighed. Both tibiae were dissected free of soft tissues. The plate and screws were removed. Either the left or right tibia, chosen randomly, was stored at $-80^{\circ} \mathrm{C}$ for mRNA analyses. The contralateral tibia was stored at $-20{ }^{\circ} \mathrm{C}$ until micro-computed tomographic (micro-CT), biomechanical, and histological analyses. The left and right muscularis gastrocnemius (MG) and muscularis soleus (MS) were extracted, weighed, and immersed in liquid nitrogen to be further stored at $-80{ }^{\circ} \mathrm{C}$ for either histological or enzyme analysis.

\section{Serum Analyses}

Analyses of serum alkaline phosphatase (Alp), osteocalcin (Oc) and creatine kinase $(\mathrm{Ck})$ were conducted at the Department of Clinical Chemistry, University Medical Center Goettingen, using an automated chemistry analyzer (Roche/Hitachi Modular) and commercially available kits (Roche) according to the manufacturer's instructions (Roche Diagnostics, Mannheim, Germany). Alp was measured using a colorimetric assay, Oc was determined using an electrochemiluminescence immunoassay, and $\mathrm{Ck}$ was assayed by the "reverse reaction" and activation by acetylcysteine.

\section{Bone Healing Analyses}

Biomechanical testing was performed using a three-point bending test [14] with the aid of a testing machine (type 145660 Z020/TND) and Test Expert Software (Zwick/ Roell, Ulm, Germany). The thawed tibia was loaded at the osteotomy line of the ventral metaphysis. Nondestructive measurements were stopped automatically by the software when the elastic deformation reached the end point (yield load). Stiffness was defined as the slope of the linear rise of the curve.

Thereafter, the tibia was scanned using micro-CT (eXplore Locus SP-Scanner; GE Healthcare, Ontario, Canada) [15]. The scan protocol was as follows: $72 \mathrm{kVp}, 90 \mu \mathrm{A}$, $1,600 \mathrm{~ms}$ exposure time, $360^{\circ}$ rotation, $0.029 \mathrm{~mm}$ pixel size, and 900 views. A 3D reconstruction was performed with the aid of the MicroView-Program (v2.1.2, GE Healthcare). After reconstruction of the data, the analysis was conducted using a newly developed bone analysis program. The 3D measurement area extended $2.5 \mathrm{~mm}$ proximally and distally from the osteotomy line (Fig. 1a). The following parameters were quantified: total bone volume (BV) and mineral density, callus and cortical densities, and bone volume per total volume fraction (BV/TV). The data were converted into $B M D\left(\mathrm{~g} / \mathrm{cm}^{3}\right)$ using a linear regression equation, $\mathrm{BMD}=0.23 \times($ value +0.55$)$, that was formulated by measuring three hydroxyapatite standards of several mineral densities.

For histological analyses, the tibia was subjected to sequential ascending concentrations of ethanol and embedded in methylmethacrylate (Merck). Sections of $150 \mu \mathrm{m}$ thickness were cut longitudinally at a right angle to the implant bed using a diamond saw microtome (SP 1600; Leica Instruments, Nussloch, Germany). The time of the osseous bridging of the osteotomy gap was determined by analyzing fluorochromelabeled callus tissue using at least 10 sections with the aid of a Leica microscope (Leitz DM RXE) [13]. Three representative central sections of the tibia were microradiographed using the Faxitron Cabinet X-ray system (Hewlett-Packard, Buffalo Grove, IL) and Kodak Industrex film (SR45, 100 NIF; Kodak, Paris, France). Sections and microradiographs were digitalized using a digital camera (Leica DC300F) and a zoom stereo microscope (Leica MZ75) and analyzed using the QWin image analysis program (Leica, Bensheim, Germany). The
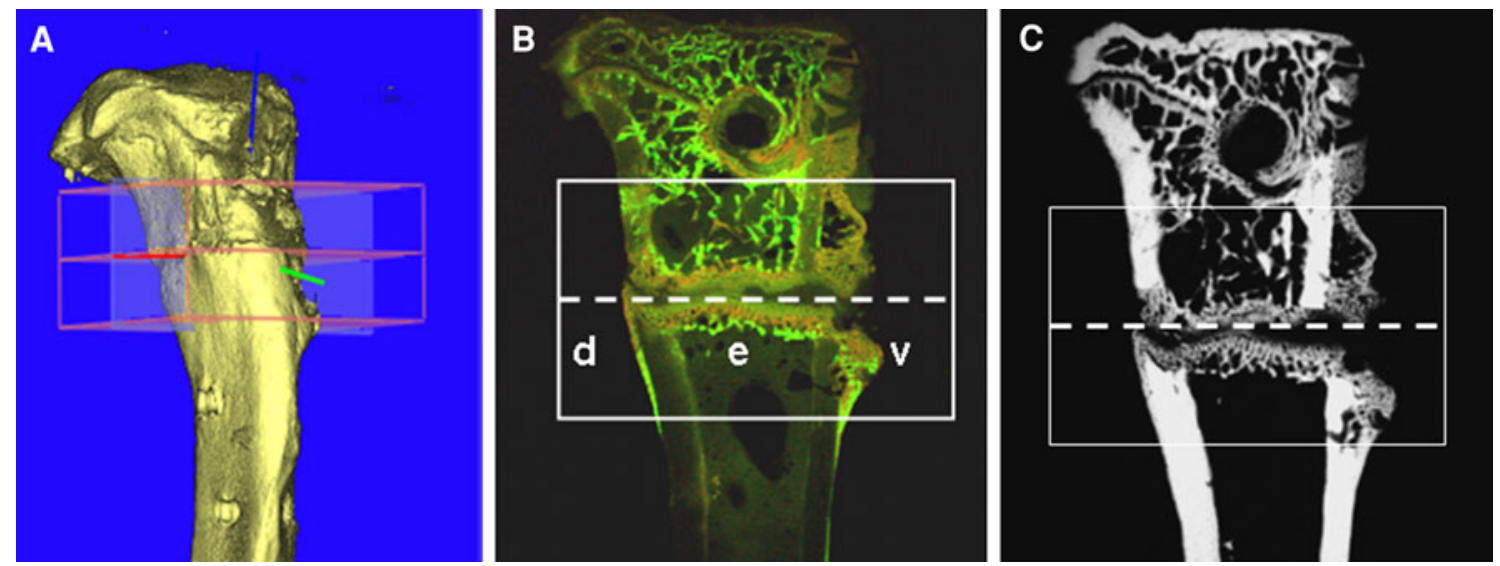

Fig. 1 Images of the measurement area extending $2.5 \mathrm{~mm}$ proximally and distally (rectangular frame) from the osteotomy line (dashed line) analyzed with the aid of micro-CT (a) and histological analyses of a fluorescence-labeled section (b) and its radiograph (c). Measurement regions: ventral $(v)$, dorsal $(d)$, endosteal $(e)$ (experiment 2, group $30 \mathrm{~Hz}$ ) 
measurement area extended $2.5 \mathrm{~mm}$ proximally and distally from the osteotomy line (Fig. 1b, c). This area was divided into three regions of interest (ROI): (1) ventral, (2) dorsal, and (3) endosteal parts of the tibia (Fig. 1b). The cortical width and density distal to the osteotomy line, periosteal callus width and density, endosteal callus density, and trabecular density and width were measured in microradiographs (Fig. 1c) [10]. The callus area $\left(\mu \mathrm{m}^{2}\right)$ was measured according to the ROI and fluorescence labeling in histological sections (Fig. 1b). The xylenol orange-labeled area was relatively small and, therefore, assessed along with the calcein-labeled area.

\section{Analyses of Gene Expression at the Osteotomy Site}

The metaphyseal part of the contralateral tibia containing newly formed callus was homogenized using a micro-dismembrator S (Sartorius, Goettingen, Germany). Total cellular RNA was extracted using the RNeasy ${ }^{\mathrm{TM}}$ Mini Kit (Qiagen, Hilden, Germany) and reverse-transcribed by Superscript ${ }^{\mathrm{TM}}$ RNase H-reverse transcriptase (Promega, Mannheim, Germany). Expression of rat genes Alp, Oc, insulin-like growth factor-1 (Igf-1), receptor activator of nuclear factor kB ligand (Rankl), osteoprotegerin (Opg), and tartrate-resistant acid phosphatase (Trap) was determined using quantitative real-time polymerase chain reaction (PCR) based on SYBR green detection (PCR QuantiTect Sybr ${ }^{\circledR}$ Green Kit, Qiagen) in an iCycler (CFX96, Bio-Rad Laboratories, Munich, Germany). Ready-to-use primer pairs were obtained from Qiagen (QuantiTect Primer Assays). The quantitative real-time PCR was carried out according to the manufacturer's instructions. Gene expression was calculated using the $2^{-\triangle \Delta C T}$ method [16], and the results are shown relative to the gene expression in untreated female rats (nonOVX, nonosteotomized) that were of the same age as the experimental animals and of comparable $\mathrm{BW}$. The reference gene was $\beta_{2}$-microglobulin.

\section{Muscle Analyses}

Muscle samples were cut into serial cross sections of $12 \mu \mathrm{m}$ thickness using a cryostat (Frigocut 2800E, Leica Instruments).

For analysis of muscle fibers, sections were fixed in a $1 \%$ paraformaldehyde solution ( $\mathrm{pH}$ 6.6) containing $1 \% \mathrm{CaCl}_{2}$ and $6 \%$ sucrose. Thereafter, muscle fibers were stained by incubation in a reduced nicotinamide adenine dinucleotide diaphorase (NADH-diaphorase) solution ( $\mathrm{pH}$ 7.4), followed by acidic incubation ( $\mathrm{pH} 4.2$ ) and incubation in adenosine$5^{\prime}$-triphosphate solution ( $\mathrm{pH}$ 9.4) [17]. Muscle fibers were classified as fast-twitch glycolytic (G), fast-twitch oxidative $(\mathrm{O})$, and slow-twitch $\mathrm{O}$ types according to Peter et al. [18]. The fast- and slow-twitch $\mathrm{O}$ fiber types were combined for analysis. Cross-sectional areas (CSAs) of at least $90 \mathrm{O}$ and 90
G fibers determined within three fields of the cross section (30 fibers/type within a field of $1 \mathrm{~mm}^{2}$ ) were measured. In the MS, only $\mathrm{O}$ fibers were measured as the MS mainly consists of these fibers [19].

For analysis of muscle capillaries, sections were fixed in $100 \%$ ethanol/chloroform/glacial acid at a ratio of 16:3:1 at $4{ }^{\circ} \mathrm{C}$ for $1 \mathrm{~h}$. Thereafter, sections were incubated in $0.3 \% \alpha$ amylase solution, treated with $1 \%$ periodic acid, and stained in Schiff's reagent solution (Roth) [20]. Finally, sections were treated with a $10 \%$ potassium sulfite solution. The capillaries and fibers found in three randomly selected fields $\left(1 \mathrm{~mm}^{2}\right.$ each) within a cross section were counted. The ratio of capillaries to muscle fibers was determined in the analyses.

For the analyses of muscle enzymes, muscle samples were weighed and homogenized in ice-cold Chappel-Perry medium $\left(0.1 \mathrm{M} \mathrm{KCl}, 0.05 \mathrm{M}\right.$ Tris, $0.01 \mathrm{M} \mathrm{MgCl}_{2} \times 6 \mathrm{H}_{2} \mathrm{O}, 1 \mathrm{mM}$ EGTA, pH 7.5) using a Potter-S-homogenizer (B. Braun Biotech International, Melsungen, Germany). Enzyme activities were assayed using a photometer (LP6; Hach Lange, Duesseldorf, Germany). Assays were performed in triplicate at $30{ }^{\circ} \mathrm{C}$. Lactate dehydrogenase (LDH) was measured as described previously [21]. Citrate synthase (CS) activity was assayed according to Faloona and Srere [22]. Complex I activity was assayed according to Hatefi and Stiggall [23]. Protein content was determined using a BCA ${ }^{\mathrm{TM}}$ Protein Assay Kit (Pierce, Rockford, IL), a multilabel reader (Perkin Elmer Precisely Victor X4), and software version 4.0 (Perkin Elmer Life and Analytical Science, Turku, Finland). The activity of the enzymes was calculated relative to the protein content.

\section{Statistical Analyses}

Statistical analyses were conducted using the SAS program (version 9.1; SAS Institute, Cary, NC). ANOVA $(P<0.05)$ was applied to reveal the impact of the treatments on the respective variables. The effects of treatment duration were taken in the model for analyses of food intake and BW variables. The $\mathrm{BW}$ of rats taken as a covariate in the analysis of muscle weight was found to be significant $(P<0.05)$. Therefore, the muscle weight to $\mathrm{BW}$ ratio (MG/BW, MS/ BW) was analyzed. Differences between individual means were estimated using the Scheffé test $(P<0.05)$. Relative gene expression was analyzed using the nonparametric Kruskal-Wallis test and Dunn's multiple comparison test (GraphPad Prism 4.0; GraphPad Software, La Jolla, CA).

\section{Results}

Body Weight, Food Intake, and Uterus Weight

In both experiments, ovariectomy significantly affected the $\mathrm{BW}$ of rats, whereas the vibration treatments did not change 
it. At the beginning of the experiments, the mean BW did not differ $(P>0.05)$ among the groups $(238 \pm 3 \mathrm{~g}$ in experiment 1 and $240 \pm 3 \mathrm{~g}$ in experiment 2 on average). The BW of OVX rats increased sharply after ovariectomy to $332 \pm 5 \mathrm{~g}$ after 8 weeks. After osteotomy, BW dropped significantly (309 $\pm 5 \mathrm{~g}$, week 9$)$ and recovered toward the end of the experiment ( $320 \pm 5 \mathrm{~g}$, week 13). In intact rats, BW also increased during the first 8 weeks $(237 \pm 4 \mathrm{~g}$, week $0 ; 276 \pm 4 \mathrm{~g}$, week 8 on average), whereas after osteotomy, it did not change significantly over the next 5 weeks.

Vibration treatments had no effect on food intake in either experiment. In OVX rats, food intake was significantly higher than that in intact rats (OVX $23 \pm 0.5$, intact $18 \pm 0.4 \mathrm{~g} /$ rat daily on average, respectively). After osteotomy, no differences were revealed among the groups; food intake dropped to $16 \pm 0.7 \mathrm{~g} /$ rat daily (week 9). During the next 4 weeks, food intake increased to the level observed at the time of osteotomy ( $21 \pm 2 \mathrm{~g} /$ rat daily, week 13$)$.

The weight of the uterus was significantly higher in intact rats than in OVX rats, and vibration had no effect (experiment 1, intact $604 \pm 50 \mathrm{mg}$, all OVX groups $105 \pm 4 \mathrm{mg}$; experiment 2 , intact $550 \pm 35 \mathrm{mg}$, all OVX groups $119 \pm 5 \mathrm{mg}$ ).

\section{Serum Analyses}

Vibration treatments had no effect on serum levels of Alp, Oc, and Ck. The Alp level was significantly higher in all OVX groups compared to that in intact rats in both experiments (all OVX groups $79 \pm 5 \mathrm{U} / \mathrm{L}$, intact $59 \pm 3 \mathrm{U} / \mathrm{L}$ ). The level of Oc and Ck did not differ $(P>0.05)$ among the groups $(19 \pm 1$ and $10,111 \pm 1,160 \mathrm{U} / \mathrm{L}$ on average, respectively).

\section{Bone Healing Analyses}

Biomechanical analysis did not reveal differences between the treatment groups in either of the experiments. Stiffness was $45 \pm 5$ and $69 \pm 17 \mathrm{~N} / \mathrm{mm}$ in intact rats and $49 \pm 3$ and $47 \pm 6 \mathrm{~N} / \mathrm{mm}$ in all OVX groups on average in experiments 1 and 2, respectively. The yield load averaged $26 \pm 3$ and $34 \pm 8 \mathrm{~N}$ in the OVX groups; in sham rats the yield load was measured at $25 \pm 3$ and $32 \pm 7 \mathrm{~N}$ in experiments 1 and 2 , respectively.

Micro-CT analyses showed that vibration did not affect the total BMD in OVX rats in experiment 1 (Table 1). BMD was lower in the $35-, 70-$, and $90-\mathrm{Hz}$ groups than in the intact group. BV/TV increased in the $35-$ and $50-\mathrm{Hz}$ groups to the same level as that in intact rats. In experiment 2 , there were no differences in total BMD among the groups (Table 2). BV/TV was significantly lower in all OVX groups irrespective of the vibration treatments. The callus and cortical densities did not differ between the groups $(P>0.05)$ in both experiments (data not shown).

In experiment 1 , analyses of microradiographs of the histological sections revealed enhanced cortical density in the OVX rats exposed to vibrations below $90 \mathrm{~Hz}$ compared to the OVX group (Table 1). In the latter group, cortical density was significantly lower than in intact rats. Cortical width was affected by neither ovariectomy nor vibration. Endosteal callus density was improved after vibration treatments of 50,70, and $90 \mathrm{~Hz}$; and at the dorsal aspect vibrations below $90 \mathrm{~Hz}$ enhanced callus density. Callus width at the dorsal aspect of the tibia increased following treatments with $50-$ and $70-\mathrm{Hz}$ vibrations. In experiment 2 , the reduced cortical width at the ventral aspect and the callus density at the dorsal aspect were measured in rats treated with vibrations at frequencies below $90 \mathrm{~Hz}$ (Table 2). The vibration at $90 \mathrm{~Hz}$ did not change these parameters. Callus width and cortical density did not change between the groups.

In both experiments, trabecular density and width were not affected by the vibration treatments. Ovariectomy significantly diminished callus and trabecular parameters of the metaphyseal tibia.

Fluorescence analysis of the labeled callus revealed that in experiment 1 the first osseous bridging of the osteotomy gap occurred in intact rats at day 23, in OVX rats at day 26, in $35-\mathrm{Hz}$ rats at day 22 , in $50-\mathrm{Hz}$ rats at day 23 , and in $70-$ and $90-\mathrm{Hz}$ rats at day 26. In experiment 2 the first osseous bridging of the osteotomy gap occurred in intact, 30-, 70-, and $90-\mathrm{Hz}$ rats on days $18,20,21$, and 22 , respectively. In the OVX and $50-\mathrm{Hz}$ groups, osseous bridging occurred on day 23 after osteotomy. Bridging of osteotomized bone ends was observed in all rats. The total callus area did not differ between the groups in either experiment (Fig. 2a, b). In experiment 1 the callus area was enlarged after vibrations of above $35 \mathrm{~Hz}$ in OVX rats (Fig. 2a). In experiment 2 the callus area was reduced in the $70-$ and $90-\mathrm{Hz}$ groups at the dorsal aspect, whereas the endosteal callus area was increased after all vibration treatments compared to the nonvibrated OVX rats (Fig. 2b). In general, the rate of callus formation was the highest at the third week of the healing period (data not shown).

\section{Analyses of Gene Expression at the Osteotomy Site}

In experiment 1 the Oc gene was upregulated in all OVX groups, reaching a significant level in the $70-\mathrm{Hz}$ group compared to the intact group (Fig. 3a). Expression of the Trap gene was lower in the groups that were exposed to vibrations above $35 \mathrm{~Hz}$ than in nonvibrated OVX rats (Fig. 3b). In experiment 2 the Alp gene was upregulated in the $50-\mathrm{Hz}$ group compared to the OVX group (Fig. 3d). The differences in expression of the Opg, Rankl, and Igf-1 
Table 1 Vertical WBV: micro-CT and microradiographic analyses of the tibia at the osteotomy site divided into ventral, dorsal, and endosteal regions in intact and OVX rats exposed to the different vibrations (at least nine replications/treatment group, experiment 1)

\begin{tabular}{|c|c|c|c|c|c|c|c|c|c|c|c|c|}
\hline & \multicolumn{2}{|l|}{ Intact } & \multicolumn{2}{|l|}{ OVX } & \multicolumn{2}{|l|}{$35 \mathrm{~Hz}$} & \multicolumn{2}{|l|}{$50 \mathrm{~Hz}$} & \multicolumn{2}{|l|}{$70 \mathrm{~Hz}$} & \multicolumn{2}{|l|}{$90 \mathrm{~Hz}$} \\
\hline & Mean & SEM & Mean & SEM & Mean & SEM & Mean & SEM & Mean & SEM & Mean & SEM \\
\hline \multicolumn{13}{|l|}{ Micro-CT } \\
\hline Total denisty $\left(\mathrm{g} / \mathrm{cm}^{3}\right)$ & $1.50^{\mathrm{a}}$ & 0.04 & $1.45^{\mathrm{ab}}$ & 0.06 & $1.37^{\mathrm{b}}$ & 0.02 & $1.45^{\mathrm{ab}}$ & 0.04 & $1.36^{\mathrm{b}}$ & 0.02 & $1.38^{\mathrm{b}}$ & 0.02 \\
\hline $\mathrm{BV} / \mathrm{TV}(\%)$ & $59^{\mathrm{a}}$ & 4 & $47^{\mathrm{b}}$ & 2 & $52^{\mathrm{ab}}$ & 2 & $55^{\mathrm{ac}}$ & 3 & $50^{\mathrm{bc}}$ & 2 & $51^{\mathrm{bc}}$ & 2 \\
\hline \multicolumn{13}{|l|}{ Microradiogpraphy } \\
\hline \multicolumn{13}{|l|}{ Ventral } \\
\hline Cortical width (mm) & 0.47 & 0.02 & 0.51 & 0.03 & 0.50 & 0.02 & 0.51 & 0.02 & 0.51 & 0.02 & 0.53 & 0.02 \\
\hline Cortical density (\%) & $100^{\mathrm{a}}$ & 0.02 & $95^{\mathrm{b}}$ & 0.6 & $97^{\mathrm{c}}$ & 0.3 & $98^{\mathrm{c}}$ & 0.3 & $98^{\mathrm{c}}$ & 0.2 & $97^{\mathrm{c}}$ & 0.3 \\
\hline Callus width (mm) & $0.45^{\mathrm{a}}$ & 0.03 & $0.57^{\mathrm{bc}}$ & 0.04 & $0.52^{\mathrm{ab}}$ & 0.04 & $0.56^{\mathrm{bc}}$ & 0.03 & $0.64^{\mathrm{c}}$ & 0.04 & $0.62^{\mathrm{bc}}$ & 0.03 \\
\hline Callus density (\%) & $86^{\mathrm{a}}$ & 1.6 & $72^{\mathrm{b}}$ & 1.8 & $66^{\mathrm{b}}$ & 2.4 & $65^{\mathrm{b}}$ & 3.3 & $72^{\mathrm{b}}$ & 2.8 & $69^{\mathrm{b}}$ & 2.8 \\
\hline \multicolumn{13}{|l|}{ Dorsal } \\
\hline Cortical width (mm) & 0.77 & 0.04 & 0.76 & 0.04 & 0.68 & 0.03 & 0.74 & 0.03 & 0.77 & 0.03 & 0.80 & 0.05 \\
\hline Cortical density (\%) & $100^{\mathrm{a}}$ & 0.01 & $97^{\mathrm{b}}$ & 0.4 & $98^{\mathrm{cd}}$ & 0.4 & $99^{\mathrm{d}}$ & 0.2 & $98^{\mathrm{d}}$ & 0.2 & $97^{\mathrm{bc}}$ & 0.4 \\
\hline Callus width (mm) & $0.71^{\mathrm{a}}$ & 0.04 & $0.74^{\mathrm{a}}$ & 0.03 & $0.76^{\mathrm{a}}$ & 0.05 & $0.89^{\mathrm{bc}}$ & 0.05 & $0.94^{\mathrm{c}}$ & 0.05 & $0.79^{\mathrm{ab}}$ & 0.04 \\
\hline Callus density (\%) & $92^{\mathrm{a}}$ & 1.3 & $71^{\mathrm{b}}$ & 2.1 & $77^{\mathrm{c}}$ & 1.8 & $80^{c}$ & 2.1 & $81^{\mathrm{c}}$ & 1.6 & $76^{\mathrm{bc}}$ & 1.9 \\
\hline \multicolumn{13}{|l|}{ Endosteal } \\
\hline Callus density (\%) & $90^{\mathrm{a}}$ & 1.6 & $65^{\mathrm{b}}$ & 1.5 & $67^{\mathrm{bc}}$ & 2.6 & $71^{\mathrm{cd}}$ & 2.7 & $82^{\mathrm{e}}$ & 1.3 & $73^{\mathrm{d}}$ & 1.6 \\
\hline Trabecular density $(\%)$ & $13^{\mathrm{a}}$ & 2.1 & $2^{\mathrm{b}}$ & 0.4 & $3^{\mathrm{b}}$ & 0.7 & $4^{\mathrm{b}}$ & 0.7 & $4^{\mathrm{b}}$ & 0.4 & $3^{\mathrm{b}}$ & 1.0 \\
\hline Trabecular width $(\mu \mathrm{m})$ & $4.5^{\mathrm{a}}$ & 0.2 & $2.5^{\mathrm{b}}$ & 0.2 & $2.5^{\mathrm{b}}$ & 0.3 & $2.2^{\mathrm{b}}$ & 0.2 & $2.3^{\mathrm{b}}$ & 0.1 & $2.5^{\mathrm{b}}$ & 0.2 \\
\hline
\end{tabular}

$\overline{\mathrm{a}-\mathrm{e}}$ Between treatment groups, means with different superscripts differ significantly $(P<0.05$, Scheffé test)

Table 2 Horizontal WBV: micro-CT and microradiographic analyses of the tibia at the osteotomy site divided into ventral, dorsal, and endosteal regions in intact and OVX rats exposed to the different vibrations (at least 11 replications/treatment group, experiment 2)

\begin{tabular}{|c|c|c|c|c|c|c|c|c|c|c|c|c|}
\hline & \multicolumn{2}{|l|}{ Intact } & \multicolumn{2}{|l|}{ OVX } & \multicolumn{2}{|l|}{$30 \mathrm{~Hz}$} & \multicolumn{2}{|l|}{$50 \mathrm{~Hz}$} & \multicolumn{2}{|l|}{$70 \mathrm{~Hz}$} & \multicolumn{2}{|l|}{$90 \mathrm{~Hz}$} \\
\hline & Mean & SEM & Mean & SEM & Mean & SEM & Mean & SEM & Mean & SEM & Mean & SEM \\
\hline \multicolumn{13}{|l|}{ Micro-CT } \\
\hline Total denisty $\left(\mathrm{g} / \mathrm{cm}^{3}\right)$ & 1.37 & 0.04 & 1.27 & 0.02 & 1.31 & 0.03 & 1.32 & 0.02 & 1.29 & 0.02 & 1.30 & 0.04 \\
\hline $\mathrm{BV} / \mathrm{TV}(\%)$ & $42^{\mathrm{a}}$ & 3 & $34^{\mathrm{b}}$ & 2 & $34^{\mathrm{b}}$ & 2 & $32^{\mathrm{b}}$ & 2 & $32^{\mathrm{b}}$ & 3 & $29^{\mathrm{b}}$ & 1 \\
\hline \multicolumn{13}{|l|}{ Microradiogpraphy } \\
\hline \multicolumn{13}{|l|}{ Ventral } \\
\hline Cortical width (mm) & $0.47^{\mathrm{ab}}$ & 0.02 & $0.49^{\mathrm{a}}$ & 0.02 & $0.43^{\mathrm{bc}}$ & 0.02 & $0.41^{\mathrm{c}}$ & 0.02 & $0.43^{\mathrm{bc}}$ & 0.02 & $0.45^{\mathrm{ac}}$ & 0.02 \\
\hline Cortical density (\%) & 100 & 0.04 & 100 & 0.14 & 99 & 0.17 & 99 & 0.25 & 100 & 0.11 & 100 & 0.12 \\
\hline Callus width (mm) & 0.50 & 0.04 & 0.48 & 0.03 & 0.51 & 0.03 & 0.51 & 0.08 & 0.47 & 0.04 & 0.40 & 0.02 \\
\hline Callus density (\%) & $79^{\mathrm{a}}$ & 2 & $68^{\mathrm{b}}$ & 2 & $62^{\mathrm{b}}$ & 3 & $66^{\mathrm{b}}$ & 3 & $66^{\mathrm{b}}$ & 3 & $66^{\mathrm{b}}$ & 3 \\
\hline \multicolumn{13}{|l|}{ Dorsal } \\
\hline Cortical width (mm) & 0.51 & 0.05 & 0.55 & 0.03 & 0.62 & 0.04 & 0.59 & 0.02 & 0.56 & 0.04 & 0.64 & 0.03 \\
\hline Cortical density (\%) & 100 & 0.09 & 100 & 0.10 & 99 & 0.24 & 99 & 0.36 & 100 & 0.14 & 100 & 0.08 \\
\hline Callus width (mm) & 1.02 & 0.14 & 0.79 & 0.08 & 0.90 & 0.07 & 0.86 & 0.05 & 0.78 & 0.05 & 0.95 & 0.07 \\
\hline Callus density (\%) & $83^{\mathrm{a}}$ & 2 & $76^{\mathrm{ab}}$ & 3 & $66^{\mathrm{c}}$ & 3 & $73^{\mathrm{b}}$ & 2 & $74^{\mathrm{b}}$ & 3 & $76^{\mathrm{ab}}$ & 2 \\
\hline \multicolumn{13}{|l|}{ Endosteal } \\
\hline Callus density (\%) & 82 & 3 & 67 & 3 & 62 & 3 & 62 & 3 & 66 & 3 & 71 & 3 \\
\hline Trabecular density (\%) & $20^{\mathrm{a}}$ & 3 & $10^{\mathrm{b}}$ & 3 & $10^{\mathrm{b}}$ & 2 & $9^{\mathrm{b}}$ & 2 & $8^{\mathrm{b}}$ & 1 & $8^{\mathrm{b}}$ & 2 \\
\hline Trabecular width $(\mu \mathrm{m})$ & $5^{\mathrm{a}}$ & 0.3 & $4^{\mathrm{b}}$ & 0.3 & $3^{\mathrm{b}}$ & 0.2 & $3^{\mathrm{b}}$ & 0.2 & $4^{\mathrm{b}}$ & 0.3 & $3^{\mathrm{b}}$ & 0.2 \\
\hline
\end{tabular}

${ }^{\mathrm{a}-\mathrm{c}}$ Between treatment groups, means with different superscripts differ significantly $(P<0.05$, Scheffé test $)$ 


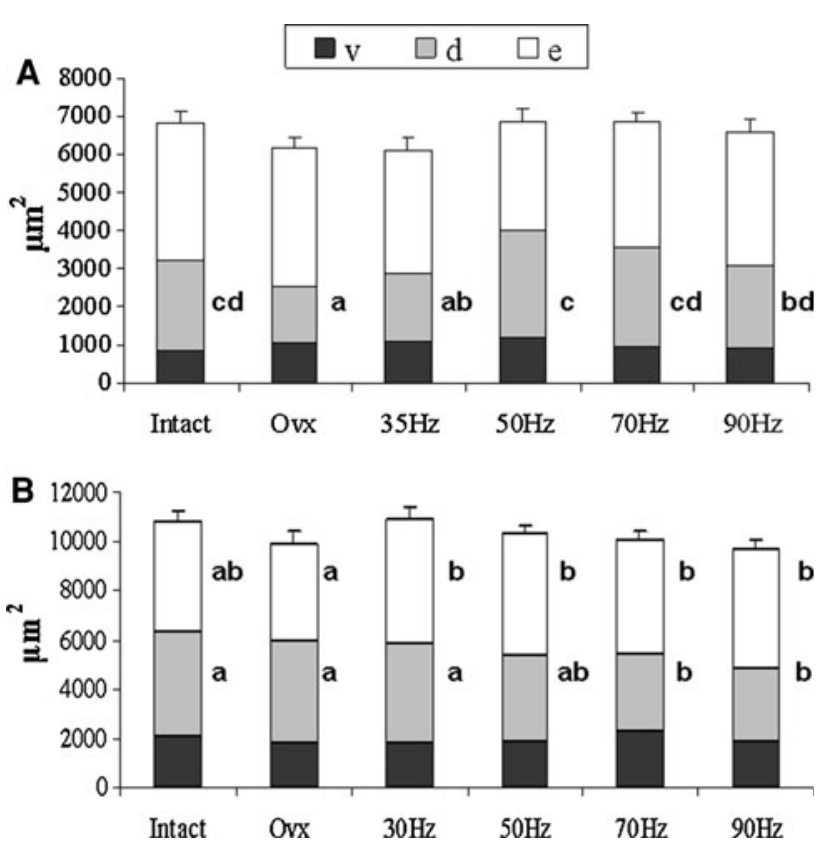

Fig. 2 Total callus area $\left(\mu \mathrm{m}^{2}\right)$ measured in fluorescence-labeled sections of the tibia divided into ventral $(v)$, dorsal $(d)$, and endosteal (e) regions in intact and OVX rats exposed to the different vibrations (30-90 Hz). Means with different letters differ significantly between the treatment groups, at the dorsal or endosteal region $(P<0.05$, Scheffé test). a Vertical WBV (experiment 1), b horizontal WBV (experiment 2)

genes were not significant between the treatment groups in either experiment (data not shown).

\section{Muscle Analyses}

The weights of the MG and MS did not differ significantly among the groups in either experiment. The MG weight was $1.99 \mathrm{~g}(\mathrm{SEM}=0.9)$ on average, and the MS weight averaged $0.13 \pm 0.01 \mathrm{~g}$. In experiment 1 , the $\mathrm{MG} / \mathrm{BW}$ ratio increased in the $50-\mathrm{Hz}$ group to the level observed in intact rats, whereas in the other groups the MG/BW ratio was lower (Table 3). In experiment 2 differences in the $\mathrm{MG} / \mathrm{BW}$ ratio were not detected (Table 4).

In experiment 1 neither muscle fiber size nor capillary density differed significantly between the treatment groups in either of the muscles that were studied (Table 3). In experiment 2 the CSA of the oxidative fibers decreased in the MG from rats in the $35-$ and $70-\mathrm{Hz}$ groups compared to that from rats in the OVX and intact groups (Table 4). The size of the $\mathrm{G}$ fibers did not change among the groups. Capillary density was significantly enhanced in the MS of rats from the $70-$ and $90-\mathrm{Hz}$ groups compared to the OVX and intact groups (Table 4).

The activity of CS increased gradually with increasing frequencies of vertical vibration in the MS, reaching a significant level in the $35-\mathrm{Hz}$ group compared to intact rats
(Table 3). Compared to the OVX group, vibration exerted a significant effect at $50 \mathrm{~Hz}$ and higher. In the MG, CS activity did not change between the groups. The LDH and complex I activities did not differ significantly between the groups in either the MG or the MS. In experiment 2, there were no differences detected in the activities of the enzymes (Table 4).

\section{Discussion}

Several reviews on WBV application for the improvement of the musculoskeletal system and bone healing have revealed the need for systematic studies to investigate variations in the vibration characteristics and the optimal dose-response relationship to determine the underlying mechanisms of muscle and bone adaptations, efficacy, and clinical relevance $[3,9,24,25]$. The present study was conducted to compare for the first time the effectiveness of either horizontal or vertical WBV over a wide range of frequencies for promoting bone healing and muscle function in ovariectomy-induced osteopenic rats. Ovariectomy was confirmed by atrophied uterine horns. Increased BW and food intake in the OVX rats have been previously reported after ovariectomy [13]. Short exposure to vertical and horizontal vibrations exerted no effect on the BW or food intake of rats.

\section{Bone Healing}

In general, vertical vibration treatments improved cortical and callus densities to some extent and enlarged the periosteal callus area and width. Horizontal vibrations did not ameliorate the impaired cortical and callus parameters in OVX rats. Moreover, horizontal vibrations reduced the cortical width at the ventral aspect and callus area and dorsally reduced the density. In these vibrated rats, the better stabilization of the osteotomy gap was most likely achieved due to the increased endosteal callus area. Although a biomechanically stable fixation was used, different vibrations could evoke movements at the fracture site, which may have differing effects on bone healing. Previously, it was reported that axial micromovements of fractured bone ends, such as those that occur with weight bearing, compression force, or bending movements, are favorable for fracture healing [26, 27], whereas shearing movements are injurious [28]. We generated movements in either the vertical or the horizontal plane. However, the force was applied indirectly to the fracture site and transmitted via the surrounding tissues and T-plate. The effect of horizontal force on fracture healing was ambiguous. Additional studies are under way to clarify this issue. 
Fig. 3 Box plot illustrating the relative mRNA expression level of $\mathbf{a}, \mathbf{b}$ Oc, $\mathbf{c}, \mathbf{d}$ Alp, and $\mathbf{e}$, f Trap genes in OVX rats, either untreated or exposed to the vertical (first column, experiment 1) or horizontal (second column, experiment 2) vibration treatment, and intact rats, calculated using the $2^{-\Delta \Delta \mathrm{CT}}$ method. Each treatment was conducted with at least 10 replications. Medians with different letters differ significantly $(P<0.05$, Dunn test)
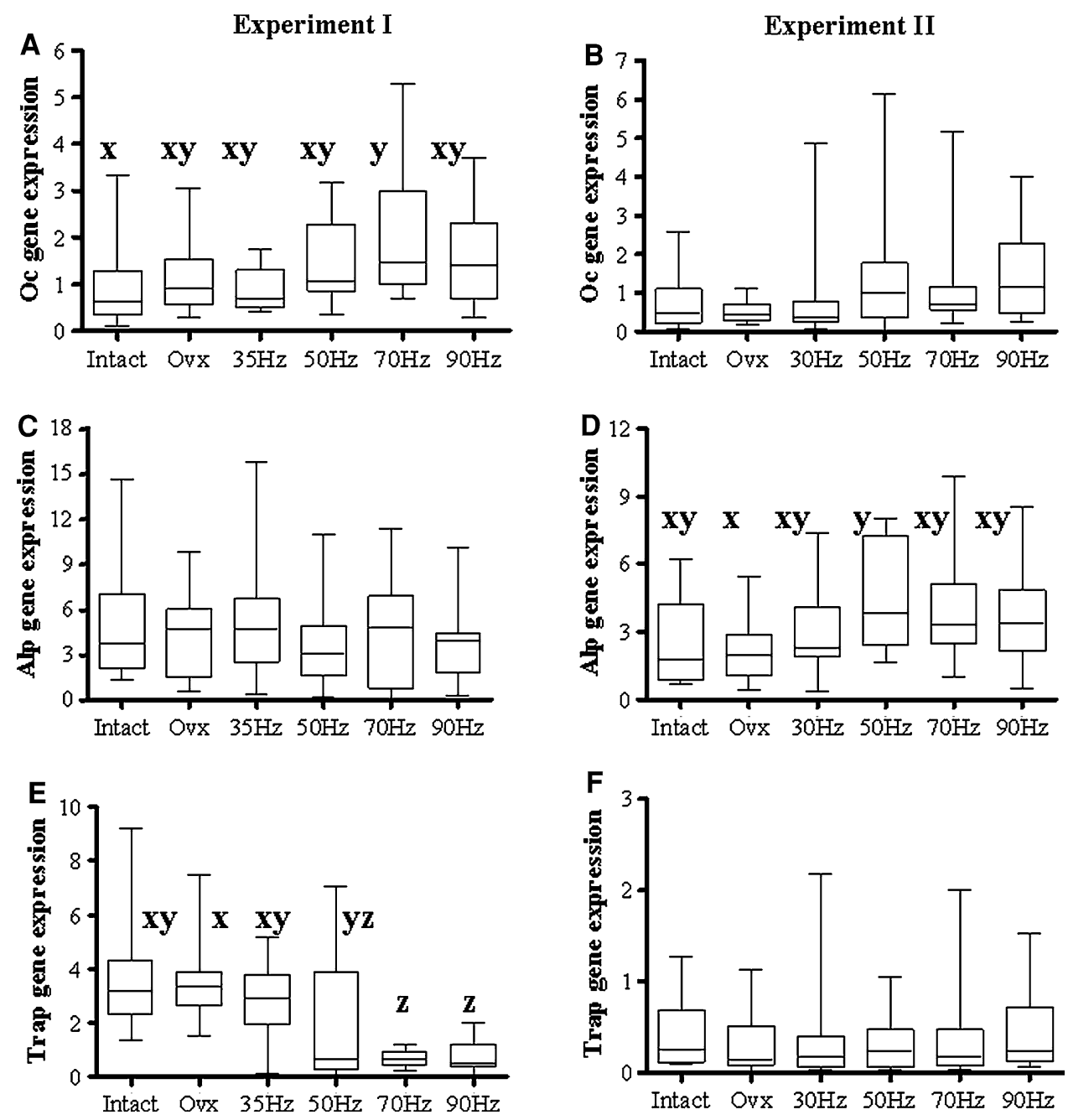

Rat limbs are naturally exposed to forces in a vertical direction during movement or jumping and weight bearing, whereas horizontal stimuli seldom occur in nature. Some authors have demonstrated increased callus area and density at the fracture site after mechanical stimulation, such as $2 \mathrm{D}$ (vertical and horizontal) vibration of $25 \mathrm{~Hz}$ for 20 or $60 \mathrm{~min} /$ day in rabbit fibula [29] and vertical vibration of $35 \mathrm{~Hz}$ for $20 \mathrm{~min} /$ day in rat femora [30]. Wolf et al. [31] reported no effect of daily WBV $(20 \mathrm{~Hz}, 5 \mathrm{~min})$ on healing of ovine metatarsus. These authors investigated skeletally mature and healthy animals. In OVX rats, a WBV of $35 \mathrm{~Hz}$ (20 min, 5 days/week) promoted callus formation, mineralization, and remodeling [32, 33]. In our previous study, we showed that a vertical vibration regime $(90 \mathrm{~Hz}, 15 \mathrm{~min}$ twice a day) improved musculoskeletal tissue but that it was not favorable for bone healing in OVX rats [10].

Micro-CT analysis has been shown to have many advantages and is accepted as an alternative to histological analysis, which is considered the gold-standard method of examination of bone specimens [34]. In this study, histological analyses permitted a more detailed assessment of the callus parameters and bone healing than micro-CT. Further development of computer software for micro-CT is under way to better assess cortical and callus tissues at the osteotomy site. The decreased total density determined by micro-CT in the vibrated groups could be explained by the enlarged callus volume in these groups, which was less compact than the cortical bone. Density was calculated over the entire volume.

The biomechanical test did not reveal differences between the treatment groups in either experiment. As previously stated, the callus biomechanical properties do not correlate with histomorphological parameters [10, 12]. Callus quality may depend on a noncalcified callus, which was not assessed histologically. Analysis of fluorochrome-labeled sections showed that the vibration treatments did not impede osseous bridging of the osteotomy gap, which occurred during the third and fourth weeks after osteotomy. Moreover, the vibration treatments of 35 and $50 \mathrm{~Hz}$ (vertical) accelerated the delayed osteotomy bridging in OVX rats.

Based on our investigation of mRNA expression of bone-related genes in the callus, different responses were observed after vertical and horizontal vibration treatments. 
Table 3 Vertical WBV: muscle weight to BW ratio, cross-sectional area (CSA) of the glycolytic (G) and oxidative (O) fibers, and activity of $\mathrm{LDH}, \mathrm{CS}$, and complex $\mathrm{I}$ in the gastrocnemius (MG) and soleus (MS) muscles of intact and OVX rats exposed to the different vibrations (at least nine replications per treatment group, experiment 1)

\begin{tabular}{|c|c|c|c|c|c|c|c|c|c|c|c|c|}
\hline & \multicolumn{2}{|l|}{ Intact } & \multicolumn{2}{|l|}{ OVX } & \multicolumn{2}{|l|}{$35 \mathrm{~Hz}$} & \multicolumn{2}{|l|}{$50 \mathrm{~Hz}$} & \multicolumn{2}{|l|}{$70 \mathrm{~Hz}$} & \multicolumn{2}{|l|}{$90 \mathrm{~Hz}$} \\
\hline & Mean & SEM & Mean & SEM & Mean & SEM & Mean & SEM & Mean & SEM & Mean & SEM \\
\hline \multicolumn{13}{|c|}{ Muscle weight to BW (mg/g) } \\
\hline MG/BW & $6.9^{\mathrm{a}}$ & 0.1 & $6.2^{\mathrm{bc}}$ & 0.1 & $6.3^{\mathrm{bc}}$ & 0.2 & $6.5^{\mathrm{ab}}$ & 0.2 & $6.3^{\mathrm{bc}}$ & 0.1 & $5.9^{\mathrm{c}}$ & 0.2 \\
\hline MS/BW & 0.47 & 0.03 & 0.40 & 0.01 & 0.44 & 0.02 & 0.45 & 0.02 & 0.42 & 0.01 & 0.42 & 0.01 \\
\hline \multicolumn{13}{|l|}{ Histology } \\
\hline \multicolumn{13}{|l|}{ MG } \\
\hline $\mathrm{CSA}, \mathrm{G}\left(\mu \mathrm{m}^{2}\right)$ & 4,723 & 152 & 4,468 & 263 & 4,838 & 178 & 4,926 & 127 & 4,280 & 214 & 4,600 & 222 \\
\hline $\mathrm{CSA}, \mathrm{O}\left(\mu \mathrm{m}^{2}\right)$ & 1,673 & 106 & 1,616 & 102 & 1,803 & 102 & 1,754 & 77 & 1,613 & 116 & 1,676 & 88 \\
\hline Capillaries/fiber & 0.78 & 0.17 & 0.82 & 0.25 & 0.86 & 0.23 & 1.01 & 0.18 & 0.87 & 0.20 & 0.95 & 0.28 \\
\hline \multicolumn{13}{|l|}{ MS } \\
\hline CSA, O $\left(\mu \mathrm{m}^{2}\right)$ & 4,687 & 109 & 4,939 & 244 & 5,517 & 240 & 4,329 & 218 & 5,032 & 485 & 5,242 & 282 \\
\hline Capillaries/fiber & 0.90 & 0.19 & 1.05 & 0.21 & 1.09 & 0.29 & 0.98 & 0.31 & 1.17 & 0.26 & 1.14 & 0.22 \\
\hline \multicolumn{13}{|l|}{ Enzymes } \\
\hline \multicolumn{13}{|l|}{ MG } \\
\hline LDH (U/mg) & 2.0 & 0.1 & 2.0 & 0.2 & 2.0 & 0.1 & 2.2 & 0.2 & 2.0 & 0.2 & 1.9 & 0.1 \\
\hline $\mathrm{CS}(\mathrm{U} / \mathrm{g})$ & 55 & 5 & 54 & 3 & 56 & 6 & 49 & 4 & 55 & 4 & 67 & 7 \\
\hline Complex I (U/g) & 3.8 & 0.7 & 4.0 & 0.7 & 4.2 & 0.8 & 2.3 & 0.4 & 2.6 & 0.6 & 3.9 & 0.7 \\
\hline \multicolumn{13}{|l|}{ MS } \\
\hline LDH (U/mg) & 0.4 & 0.01 & 0.4 & 0.04 & 0.4 & 0.03 & 0.4 & 0.02 & 0.4 & 0.03 & 0.4 & 0.05 \\
\hline $\mathrm{CS}(\mathrm{U} / \mathrm{g})$ & $29^{\mathrm{a}}$ & 4 & $31^{\mathrm{ab}}$ & 3 & $41^{\mathrm{bc}}$ & 5 & $45^{\mathrm{cd}}$ & 5 & $47^{\mathrm{cd}}$ & 4 & $56^{\mathrm{d}}$ & 2 \\
\hline Complex I (U/g) & 8.6 & 1.3 & 7.9 & 0.8 & 7.7 & 0.8 & 6.4 & 0.4 & 7.8 & 0.9 & 7.6 & 1.2 \\
\hline
\end{tabular}

$\overline{\mathrm{a}-\mathrm{d}}$ Between treatment groups, means with different superscripts differ significantly $(P<0.05$, Scheffé test)

Vertical vibration caused enhanced expression of the osteoblast gene Oc $(70 \mathrm{~Hz})$ and diminished expression of the osteoclast gene Trap $(>35 \mathrm{~Hz})$. This indicates that the callus and bone tissues at the osteotomy site were sensitive to the vertical vibrations, and their response suggested enhanced bone synthesis in these rats. Similar upregulation of the Oc gene was reported in the callus of OVX rats after $90-\mathrm{Hz}$ vibrations [10]. Differences in serum Oc levels were not detected. The gene-expression level does not directly correspond to the level of protein synthesis [35]. In rats exposed to horizontal vibrations, enhanced mRNA expression of Alp was detected. This may be a sign at the molecular level that the state of impaired bone turnover in OVX rats could be worsened after horizontal vibration. The elevated serum levels of Alp detected in both experiments can be explained by the enhanced rate of bone turnover in the OVX rats $[10,11]$.

In the present study, we reported that the most favorable frequencies for vertical vibration were 35 and $50 \mathrm{~Hz}$. The effects of 70- and $90-\mathrm{Hz}$ vibrations on bone healing were not clearly defined. Some callus and cortical parameters were improved, and the expression of bone genes could favor bone synthesis; however, bridging of the osteotomy gap occurred at the same time as in the nonvibrated OVX rats. The $90-\mathrm{Hz}$ vibration applied for 15 min twice a day was shown to impair bone healing [10]. In contrast, for nonosteotomized bone, vertical vibration at $90 \mathrm{~Hz}$ caused a stronger anabolic response than vibration at $45 \mathrm{~Hz}$ [36]. This should be taken into consideration when WBV treatments are applied to ameliorate osteoporotic bone parameters and from the perspective of bone healing.

Muscle

Similarly to the bone healing studies, muscle tissue responded to the vibration treatments differently. Reduction of the muscle to $\mathrm{BW}$ ratio was observed after ovariectomy in the MG, whereas vertical WBV of $50 \mathrm{~Hz}$ returned the muscle to $\mathrm{BW}$ ratio to the level measured in intact rats (experiment 1). These changes occurred independently of fiber size. In the muscle of mature female rodents, the CSAs of all types of fibers were reported to be unaffected by estrogen status [37, 38]. Altered metabolism in the OVX rats may be responsible for the increase in adipose tissue and BW [39]. This may lead to the reduced muscle to $\mathrm{BW}$ ratio, whereas vertical vibration demonstrated a favorable effect on this parameter in the OVX rats. 
Table 4 Horizontal WBV: muscle weight to BW ratio, crosssectional area (CSA) of the glycolytic $(\mathrm{G})$ and oxidative $(\mathrm{O})$ fibers, and activity of $\mathrm{LDH}, \mathrm{CS}$, and complex I in the gastrocnemius (MG) and soleus (MS) muscles of intact and OVX rats exposed to the different vibrations (at least 11 replications/treatment group, experiment 2)

\begin{tabular}{|c|c|c|c|c|c|c|c|c|c|c|c|c|}
\hline & \multicolumn{2}{|l|}{ Intact } & \multicolumn{2}{|l|}{ OVX } & \multicolumn{2}{|l|}{$35 \mathrm{~Hz}$} & \multicolumn{2}{|l|}{$50 \mathrm{~Hz}$} & \multicolumn{2}{|l|}{$70 \mathrm{~Hz}$} & \multicolumn{2}{|l|}{$90 \mathrm{~Hz}$} \\
\hline & Mean & SEM & Mean & SEM & Mean & SEM & Mean & SEM & Mean & SEM & Mean & SEM \\
\hline \multicolumn{13}{|c|}{ Muscle to $\mathrm{BW}$ ratio $(\mathrm{mg} / \mathrm{g})$} \\
\hline MG/BW & 6.5 & 0.2 & 6.1 & 0.3 & 6.3 & 0.2 & 6.3 & 0.2 & 6.5 & 0.1 & 6.3 & 0.2 \\
\hline $\mathrm{MS} / \mathrm{BW}$ & 0.41 & 0.01 & 0.36 & 0.01 & 0.40 & 0.02 & 0.39 & 0.01 & 0.37 & 0.02 & 0.39 & 0.04 \\
\hline \multicolumn{13}{|l|}{ Histology } \\
\hline \multicolumn{13}{|l|}{ MG } \\
\hline $\mathrm{CSA}, \mathrm{G}\left(\mu \mathrm{m}^{2}\right)$ & 5,771 & 185 & 5,975 & 177 & 5,728 & 241 & 5,673 & 194 & 5,578 & 187 & 5,811 & 238 \\
\hline $\mathrm{CSA}, \mathrm{O}\left(\mu \mathrm{m}^{2}\right)$ & $2,502^{\mathrm{a}}$ & 110 & $2,456^{\mathrm{ab}}$ & 84 & $2,192^{\mathrm{c}}$ & 69 & $2,442^{\mathrm{ad}}$ & 102 & $2,041^{\mathrm{c}}$ & 68 & $2,228^{\mathrm{bcd}}$ & 88 \\
\hline Capillaries/fiber & 1.59 & 0.06 & 1.70 & 0.11 & 1.77 & 0.09 & 1.70 & 0.08 & 1.82 & 0.06 & 1.44 & 0.17 \\
\hline \multicolumn{13}{|l|}{ MS } \\
\hline CSA, $\mathrm{O}\left(\mu \mathrm{m}^{2}\right)$ & 4,097 & 333 & 5,052 & 455 & 4,284 & 332 & 4,711 & 247 & 4,902 & 467 & 4,788 & 467 \\
\hline Capillaries/fiber & $1.70^{\mathrm{a}}$ & 0.08 & $1.96^{\mathrm{ab}}$ & 0.14 & $2.02^{\mathrm{bc}}$ & 0.05 & $2.02^{\mathrm{bc}}$ & 0.10 & $2.26^{\mathrm{c}}$ & 0.09 & $2.54^{\mathrm{d}}$ & 0.10 \\
\hline \multicolumn{13}{|l|}{ Enzymes } \\
\hline \multicolumn{13}{|l|}{ MG } \\
\hline LDH (U/mg) & 3.8 & 0.3 & 3.2 & 0.2 & 3.4 & 0.3 & 3.2 & 0.2 & 3.2 & 0.2 & 3.3 & 0.2 \\
\hline $\mathrm{CS}(\mathrm{U} / \mathrm{g})$ & 60 & 8 & 81 & 7 & 76 & 8 & 79 & 7 & 83 & 8 & 80 & 8 \\
\hline Complex I (U/g) & 4.8 & 1.2 & 6.7 & 1.3 & 5.5 & 0.8 & 7.4 & 1.5 & 6.1 & 1.0 & 6.1 & 1.3 \\
\hline \multicolumn{13}{|l|}{ MS } \\
\hline LDH (U/mg) & 0.4 & 0.03 & 0.4 & 0.04 & 0.4 & 0.05 & 0.5 & 0.09 & 0.4 & 0.06 & 0.4 & 0.05 \\
\hline $\mathrm{CS}(\mathrm{U} / \mathrm{g})$ & 87 & 12 & 89 & 14 & 86 & 11 & 103 & 15 & 88 & 12 & 90 & 7 \\
\hline Complex I (U/g) & 13.7 & 2.7 & 10.8 & 1.8 & 10.0 & 1.4 & 10.8 & 2.8 & 9.3 & 1.7 & 10.2 & 1.1 \\
\hline
\end{tabular}

$\overline{\mathrm{a}-\mathrm{d}}$ Between treatment groups, means with different superscripts differ significantly $(P<0.05$, Scheffé test)

Whereas the vertical vibrations did not affect the muscle structure, horizontal forces reduced the CSA of oxidative fibers, reaching a significant level at 35,70 , and $90 \mathrm{~Hz}$ in MG. These changes in fiber size did not correspond to the unchanged muscle weight and BW. The enhanced capillary density may be explained by the mechanical stimulus, which may have increased the blood flow and capillary shear stress, promoting angiogenesis in the muscle [40]. On the other hand, an increase in capillary density was reported to be related to the decreased fiber size [20].

In general, the metabolic enzymes studied here were not changed after the vibration treatments. The exception was CS, which increased after vertical vibrations in the MS. This may be explained by the enhanced oxidative function of the MS. The soleus muscle consists of predominantly oxidative fibers, which have the largest mean volume fraction of mitochondria among muscle fibers [18]. CS is an enzyme that is involved in the first step of the citric acid cycle. This enzyme catalyzes the condensation of acetylcoenzyme A and oxaloacetate to citrate accompanied by the liberation of acetyl-coenzyme A. CS activity is commonly used to assess metabolic capacity, including the oxidative and respiratory capacities of muscle, and the mitochondrial volume density [18]. The level of CS activity after exercise training has been reported to change from 0 to $100 \%$ [41]. In this context, the timing of muscle sampling relative to the last exercise session is critical when measuring CS [41]. In both experiments of the present study, the last exposure to the vibration treatments was performed 1 day before sample collection. Several studies on rat skeletal muscle have reported unaltered or even decreased CS levels immediately after acute exercise [42]. Savard et al. [43] reported a $30 \%$ increase in CS when rat muscle was harvested $24 \mathrm{~h}$ after acute exercise.

Metabolic adaptations to endurance exercises are believed to increase the potential of the citric acid cycle, to enhance lipid utilization, and to decrease glycolysis [44]. In the present study, neither the glycolytic enzyme (LDH) nor the oxidative phosphorylation enzyme (complex I) differed after vibration treatments. These findings indicate that the vibration treatments did not produce a sudden change in the environment of rats as a result of a sharp increase in the level of physical activity [45], and the adaptive stimulus did not alter the functional cell properties. Furthermore, the vibration treatments did not change the serum levels of $\mathrm{Ck}$, an indicator of muscle injury and other muscle diseases. 


\section{Conclusion}

One of the proposed mechanisms by which WBV exerts its effects on bone tissue is the activation of muscle, which mechanically loads the bone $[2,8]$. Another hypothesis is that WBV signals become amplified within the bone tissue by stress-generated fluid flow, thereby activating bone cells, which act as mechanosensors [2,8]. In the present study, although the osteotomized bone was fixed by a T-plate, the vibration stimuli may have directly affected bone healing by evoking the movements of the osteotomized bone ends. Vertical WBV appeared to be favorable both for bone healing and for muscle tissue. The preferable frequencies were 35 and $50 \mathrm{~Hz}$, whereas 70 and $90 \mathrm{~Hz}$ showed less effect. Horizontal WBV was found to exert no positive effect, and it affected some of the bone and muscle parameters unfavorably. These findings indicate that the type of vibration, which is often not reported in the literature [24], is an important parameter. The vibration parameters applied at rehabilitation institutes using vibration plates are largely determined by the manufacturer's recommendations. The periodicity is often selected based on common routines for strength training [1]. However, WBV protocols should be designed specifically for the treatment (improvement of osteoporotic bone structure, built-up or conservation of skeletal muscles after trauma) and for the patients, who may differ in age, hormonal status [24], bone and muscle state, fracture type, etc. Until the underlying mechanisms of the effects of WBV on different physiological systems have been elucidated, precautions have to be taken when applying WBV as a therapy for postmenopausal women and as a possible means for improvement of bone healing.

Acknowledgments The present study was supported by the German Research Foundation (DFG, STU 478/3-2). The authors are grateful to R. Castro-Machguth, A. Witt, and R. Wigger for technical support.

Open Access This article is distributed under the terms of the Creative Commons Attribution License which permits any use, distribution, and reproduction in any medium, provided the original author(s) and the source are credited.

\section{References}

1. Nordlund MM, Thorstensson A (2007) Strength training effects of whole-body vibration? Scand J Med Sci 17:12-17

2. Rubin C, Judex S, Qin YX (2006) Low-level mechanical signals and their potential as a non-pharmacological intervention for osteoporosis. Age Ageing 35:ii32-ii36

3. Slatkovska L, Alibhai SMH, Beyene J, Cheund AM (2010) Effect of whole-body vibration on BMD: a systematic review and metaanalysis. Osteoporos Int 21:1969-1980

4. Namkung-Matthai H, Appleyard R, Jansen J, Hao Lin J, Maastricht S, Swain M, Mason RS, Murrell GA, Diwan AD, Diamond $\mathrm{T}$ (2001) Osteoporosis influences the early period of fracture healing in a rat osteoporotic model. Bone 28:80-86
5. Sitnick M, Foley AM, Brown M, Spangenburg EE (2006) Ovariectomy prevents the recovery of atrophied gastocnemius skeletal muscle mass. J Appl Physiol 100:286-293

6. Yamaji T, Ando K, Wolf S, Augat P, Claes L (2001) The effect of micromovement in callus formation. J Orthop Sci 6:571-575

7. Bogaerts A, Delecluse C, Claessens AL, Coudyzer W, Boonen S, Verschueren SM (2007) Impact of whole-body vibration training versus fitness training on muscle strength and muscle mass in older men: a 1-year randomized controlled trial. J Gerontol A Biol Sci Med Sci 62:630-635

8. Fritton JC, McLeod K, Ribun CT (2000) Quantifying the strain history of bone: spatial uniformity and self-similarity of lowmagnitude strains. J Biomech 33:317-325

9. Chao EYS, Inoue N (2003) Biophysical stimulation of bone fracture repair, regeneration and remodelling. Eur Cell Mater 6:72-85

10. Stuermer EK, Komrakova M, Werner C, Wicke M, Kolios L, Sehmisch S, Tezval M, Utesch C, Mangal O, Zimmer S, Dullin C, Stuermer KM (2010) Musculoskeletal response to whole body vibration during fracture healing in healthy and ovariectomized rats. Calcif Tissue Int 87:168-180

11. Kalu DN (1991) The ovariectomized rat model of postmenopausal bone loss. Bone Miner 15:175-192

12. Stuermer EK, Sehmisch S, Rack T, Wenda E, Seidlova-Wuttke D, Tezval M, Wuttke W, Frosch KH, Stuermer KM (2010) Estrogen and raloxifene improve metaphyseal fracture healing in the early phase of osteoporosis. A new fracture-healing model at the tibia in rat. Langenbecks Arch Surg 395:163-172

13. Komrakova M, Stuermer EK, Werner C, Wicke M, Kolios L, Sehmisch S, Tezval M, Daub F, Martens T, Witzenhausen P, Dullin C, Stuermer KM (2010) Effect of human parathyroid hormone hPTH (1-34) applied at different regimes on fracture healing and muscle in ovariectomized and healthy rats. Bone 47:480-492

14. Sturmer EK, Seidlova-Wuttke D, Sehmisch S, Rack T, Wille J, Frosch KH, Wuttke W, Sturmer KM (2006) Standardized bending and breaking test for the normal and osteoporotic metaphyseal tibias of the rat: effect of estradiol, testosterone, and raloxifene. J Bone Miner Res 21:89-96

15. McNamara LM, Prendergast PJ, Schaffler MB (2005) Bone tissue material properties are altered during osteoporosis. J Musculoskelet Neuronal Interact 5:342-343

16. Livak KJ, Schmittgen TD (2001) Analysis of relative gene expression data using real-time quantitative PCR and the $2^{-\Delta \Delta \mathrm{CT}}$ method. Methods 25:402-408

17. Horák V (1983) A successive histochemical staining for succinate dehydrogenase and "reversed"-ATPase in a single section for the skeletal muscle fibre typing. Histochem Cell Biol 78:545-553

18. Peter JB, Barnard RJ, Edgerton VR, Gillespie CA, Stempel KE (1972) Metabolic profiles of the three fiber types of skeletal muscle in guinea pigs and rabbits. Biochemistry 11:2627-2633

19. Hoppeler H (1986) Exercise-induced ultrastructural changes in skeletal muscle. Int J Sports Med 7:187-204

20. Andersen P (1975) Capillary density in skeletal muscle of man. Acta Physiol Scand 95:203-205

21. Komrakova M, Krischek C, Wicke M, Sehmisch S, Tezval M, Rohrberg M, Brandsch T, Stuermer KM, Stuermer EK (2011) Influence of intermittent administration of parathyroid hormone on muscle tissue and bone healing in orchiectomized rats or controls. J Endocrinol 209:9-19

22. Faloona GR, Srere PA (1969) Escherichia coli citrate synthase. Purification and the effect of potassium on some properties. Biochemistry 8:4497-4503

23. Hatefi, Stiggall DL (1978) Preparation and properties of NADH: cytochrome c oxidoreductase (complex I-III). Methods Enzymol 53:5-10 
24. Prisby RD, Lafage-Proust MH, Malaval L, Belli A, Vico L (2008) Effect of whole body vibration in skeleton and other organ systems in man and animal models: what we know and what we need to know. Ageing Res Rev 7:319-329

25. Mikhael M, Orr R, Fiatarone Singh MA (2010) The effect of whole body vibration exposure on muscle or bone morphology and function in older adults: a systematic review of the literature. Maturitas 66:150-157

26. Sarmiento A, Schaeffer JF, Beckerman L, Latta LL, Enis JE (1977) Fracture healing in the rat femora as affected by functional weight-bearing. J Bone Joint Surg Am 59:369-375

27. Goodship AE, Kenwright J (1985) The influence of induced micromovement upon the healing of experimental tibial fractures. J Bone Joint Surg Br 67:650-655

28. Yamagishi M, Yoshimura Y (1955) The biomechanics of fracture healing. J Bone Joint Surg Am 37:1035-1068

29. Usui Y, Zerwekh JE, Vanharanta H, Ashman RB, Mooney V (1989) Different effects of mechanical vibration on bone ingrowth into porous hydroxyapatite and fracture healing in a rabbit model. J Orthop Res 7:559-567

30. Leung KS, Shi HF, Cheung WH, Qin L, Ng WK, Tam KF, Tang N (2008) Low-magnitude high-frequency vibration accelerates callus formation, mineralization, and fracture healing in rats. J Orthop Res 27:458-465

31. Wolf S, Janousek A, Pfeil J, Veith W, Haas F, Duda G, Claes L (1998) The effects of external mechanical stimulation on the healing of diaphyseal osteotomies fixed by flexible external fixation. Clin Biomech 13:359-364

32. Shi HF, Cheung W-H, Qin L, Leung AH-C, Leung K-S (2010) Low-magnitude high-frequency vibration treatment augments fracture healing in ovariectomy-induced osteoporotic bone. Bone 46:1299-1305

33. Chow DHK, Leung K-S, Qin L, Leung AH-C, Cheung W-H (2011) Low-magnitude high-frequency vibration (LMHFV) enhanced bone remodelling in osteoporotic rat femoral fracture healing. J Orthop Res 29:746-752

34. Particelly F, Mecozzi L, Beraudi A, Montesi M, Baruffaldi F, Viceconti M (2012) A comparison between micro-CT and histology for the evaluation of cortical bone: effect of polymethylmethacrylate embedding on structural parameters. J Microsc 245:302-310
35. Judex S, Lei X, Han D, Rubin C (2007) Low-magnitude mechanical signals that stimulate bone formation in the ovariectomized rat are dependent on the applied frequency but not on the strain magnitude. J Biomech 40:1333-1339

36. Meyer RA, Meyer MH, Tenholder M, Wondracek S, Wasserman R, Garges P (2003) Gene expression in older rats with delayed union of femoral fractures. J Bone Joint Surg Am 85:1243-1254

37. McClung JM, Davis JM, Wilson MA, Goldsmith EC, Carson JA (2006) Estrogen status and skeletal muscle recovery from disuse atrophy. J Appl Physiol 100:2012-2023

38. Moran AL, Nelson SA, Landisch RM, Warren GL, Lowe DA (2007) Estradiol replacement reverses ovariectomy-induced muscle contractile and myosin dysfunction in mature female mice. J Appl Physiol 102:1387-1393

39. Komrakova M, Werner C, Wicke M, Nguyen BT, Sehmisch S, Tezval M, Stuermer KM, Stuermer EK (2009) Effect of daidzein, 4-methylbenzylidene camphor or estrogen on gastrocnemius muscle of osteoporotic rats undergoing tibia healing period. J Endocrinol 201:253-262

40. Badr I, Brown MD, Egginton S, Hudlická O, Milkiewicz M, Verhaeg J (2003) Differences in local environment determine the site of physiological angiogenesis in rat skeletal muscle. Exp Physiol 88:565-568

41. Leek BT, Mudaliar SRD, Henry R, Mathieu-Costello, Richardson RS (2001) Effect of acute exercise on citrate synthase activity in untrained and trained human skeletal. Am J Physiol Regul Integr Comp Physiol 280:R441-R447

42. Ji LL, Stratman FW, Lardy HA (1988) Enzymatic down regulation with exercise in rat skeletal muscle. Arch Biochem Biophys 263:137-149

43. Savard R, Smith LJ, Palmer JE, Greenwood MRS (1987) Site specific effects of acute exercise on muscle and adipose tissue metabolism in sedentary female rats. Physiol Behav 43:65-71

44. Gollnick PD (1986) Metabolic regulation in skeletal muscle. Influence of endurance training as exerted by mitochondrial protein concentration. Acta Physiol Scand 128:53-66

45. Spina RJ, Chi MM-Y, Hopkins MG, Nemeth PM, Lowry OH, Holloszy JO (1996) Mitochondrial enzymes increase in muscle in response to 7-10 days of cycle exercise. J Appl Physiol 80:2250-2254 